\title{
Las edades en la cultura corporal: representaciones en los libros de texto de educación física de Brasil
}

\author{
ALBA GONZÁLEZ-PALOMARES \\ Universidad Pontificia de Salamanca, Salamanca, España
}

ANA ISABEL REY-CAO

Universidade de Vigo, Pontevedra, España

\section{RESUMEN}

Este estudio analiza la cultura corporal que se representa en las imágenes de los libros de texto de educación física de Brasil en función de la edad de sus protagonistas. El estudio es de tipo empírico, descriptivo y comparativo. La técnica de investigación fue el análisis de contenido mediante un instrumento de observación elaborado ad hoc. Los resultados arrojaron una representación diferenciada de la cultura corporal en función de la edad y el género. Niñez, adolescencia y juventud son las etapas predominantes. Mujeres y grupos mixtos predominan en la infancia y adolescencia; hombres en la juventud y edad adulta. La juventud se asocia a la práctica deportiva competitiva y de élite. Personas de otras edades realizan deportes individuales y actividades artísticas, en ámbitos no competitivos, espacios no deportivos y sin vinculación con la élite deportiva. La presencia de hombres y mujeres mayores está equilibrada y presenta un enfoque que les otorga importancia.

PALABRAS CLAVE

edad; cultura corporal; imágenes; libros de texto; educación física. 


\title{
THE AGES IN BODY CULTURE: REPRESENTATIONS IN BRAZILIAN PHYSICAL EDUCATION TEXTBOOKS
}

\begin{abstract}
This research analyses the body culture which is represented on images of Brazilian physical education textbooks according to the age of their protagonists. The study is empiric, descriptive and comparative. A content analysis was carried out through the elaboration of an ad hoc observational instrument. The results show a distinct representation of body culture according to age and gender. The childhood, adolescence and youth are predominant groups. Girls and mixed groups prevail on childhood and adolescence; men in youth and adulthood. The youth is associated to competitive and elite sports. People of other ages practice individual sports and artistic activities, in non-competitive fields, non-sportive environments and without bounds to elite sports. Among older people, men and women are equally represented in a way that the focus transmits importance.
\end{abstract}

KEYWORDS

age; body culture; images; textbooks; physical education.

\section{AS IDADES NA CULTURA CORPORAL: REPRESENTAÇÕES NOS LIVROS DIDÁTICOS DE EDUCAÇÃO FÍSICA DO BRASIL}

\author{
RESUMO
}

Este estudo analisa a cultura corporal que se representa nas imagens dos livros didáticos de educação física do Brasil de acordo com a idade de seus protagonistas. $\mathrm{O}$ estudo é de tipo empírico, descritivo e comparativo. A técnica de investigação foi a análise de conteúdo mediante instrumento de observação elaborado ad hoc. Os resultados apresentaram uma representação diferenciada da cultura corporal de acordo com a idade e o gênero. Infância, adolescência e juventude são as etapas predominantes. Mulheres e grupos mistos predominam na infância e adolescência; homens na juventude e idade adulta. A juventude se associa à prática esportiva competitiva e de elite. Pessoas de outras idades realizam esportes individuais e atividades artísticas em âmbitos não competitivos, espaços não desportivos e sem vinculação com a elite desportiva. A presença de homens e mulheres mais velhos é equilibrada e apresenta um enfoque que lhes concede importância.

idade; cultura corporal; imagens; livros didáticos; educação física. 


\section{INTRODUCCIÓN}

Los libros de texto reproducen un imaginario que reduce la complejidad propia de la realidad social y condiciona creencias sesgadas en el alumnado (Gallardo, 2001; Jorquera, 2010). Los manuales escolares constituyen así un sistema representacional que actúa como utillaje mental muy poderoso. Los datos de diversas investigaciones indican que los prejuicios están presentes en los manuales escolares de múltiples materias (Goldstein, Siegel y Seaman, 2010; Knudsen, 2005; Oliveira, 2008; Rey-Cao, Táboas-Pais y Canales Lacruz, 2013; Sleeter y Grant, 2011; Táboas, 2009). Especialmente las fotografías de los libros de texto encierran un elevado potencial infopersuasivo porque construyen mensajes que no se perciben conscientemente y que poseen una gran capacidad inductora de conductas imitativas (Gubern, 2005; Joly, 2003). Entre los 12 y 15 años existe una tendencia a legitimar la identidad a través de la imagen, pues esta se percibe como realidad innegable (Revuelta, 2008). La utilización de la cámara - a través de diferentes planos, enfoques, códigos lumínicos, etc. - puede enfatizar, dramatizar o disimular aquello que se quiere mostrar y transmitir mensajes cargados de subjetividad. Los enfoques contrapicados caracterizan al personaje como poderoso e importante, mientras que los enfoques picados condicionan una percepción de la persona fotografiada como débil y menos importante (Alonso y Matilla, 1990).

La calidad de un sistema educativo se mide, entre otros criterios, por su funcionalidad. Su capacidad para ajustar sus objetivos y, a través de ellos, los productos, acciones y medios de que dispone, a las funciones que le han sido asignadas por la sociedad (De la Orden, 2009). El sistema educativo transmite, entre otras, determinadas dimensiones de la cultura corporal. La cultura corporal de una sociedad puede conceptualizarse como "el conjunto de valores, usos, saberes, creencias, normas y pautas de conducta que delimitan las apreciaciones y prácticas corporales en un determinado contexto social en el que vivimos" (Barbero, 2001, p. 22). La cultura corporal que es hegemónica en la actualidad, lejos de brindar un panorama favorecedor de la diversidad cultural, desempeña un papel decisivo en la configuración y establecimiento de unos usos corporales muy adecuados a la lógica del capitalismo (Barbero, 2006; Caspistegui, 2012; Vicente, 2003) y a una racionalidad antropológica de la discriminación en la que "el cuerpo atlético se propone como la expresión más elevada de las virtudes físicas y morales, mientras que el cuerpo deficitario exhibe taras y defectos que marcan el límite de lo inhumano" (Moreno, 2013, p. 52). Valores como el esfuerzo, la masculinidad, la fortaleza física, la superación y el rendimiento han caracterizado la cultura corporal de la modernidad, cuyo máximo exponente es el deporte (Caspistegui, 2012; Elias y Dunning, 1992; Olivera y Olivera, 1995). En la modernidad líquida, propia del capitalismo tardío, estos valores se han filtrado también en la cultura de la forma (Bauman, 2000) con el apogeo de las tecnologías disciplinantes del cuerpo y el ejercicio físico (Barbero, 2006; Gómez, 2008).

No obstante la calidad de la transmisión de la cultura corporal debería evaluarse en función de la consecución de uno de los objetivos generales de la educación física presentes en los Parámetros Curriculares Nacionales para la Enseñanza 
Fundamental (PCNs) (Brasil, 1998, p. 33). Este establece que el alumnado tiene que ser capaz de:

participar de atividades corporais, estabelecendo relações equilibradas e construtivas com os outros, reconhecendo e respeitando características físicas e de desempenho de si próprio e dos outros, sem discriminar por características pessoais, físicas, sexuais ou sociais;

Del mismo modo, el artículo 22, Capítulo V del Estatuto do Idoso (Brasil, 2003) establece que:

Nos currículos mínimos dos diversos níveis de ensino formal serão inseridos conteúdos voltados ao processo de envelhecimento, ao respeito e à valorização do idoso, de forma a eliminar o preconceito e a produzir conhecimentos sobre a matéria.

La educación física en Brasil ha experimentado a partir de la década 1980 una pulsión renovadora encaminada a la diversificación de sus contenidos. Se han incorporado al currículum mayor diversidad de prácticas corporales del universo de la cultura corporal con la intención de evitar los sesgos propios del proceso deportivizador y la hegemonía de contenidos, fundamentalmente vinculados con la estética y la salud (Gómes da Silva, Imbiriba y Agatti, 2015), que marginan a determinados colectivos. Pero en este proceso se ha discutido poco al respecto de la función que tiene el libro de texto de EF, hasta el punto que ningún libro de esta disciplina había sido sometido en el año 2011 al Programa Nacional do Libro Didáctico (Botelho y Neira, 2014; Rodrigues y Darido, 2011).

La educación formal debe mediar en este proceso porque es un importante agente promotor de comportamientos, valores, creencias, y expectativas realistas y contextualizadas con respecto a las personas de edad (Cachioni y Aguilar, 2008). Una cuestión importante en la práctica pedagógica es la visión del mundo del alumnado, así como la relación entre esa visión y los modelos que se le transmiten a través de situaciones educativas (Fleuri, 2003). Este estudio incide en el análisis del contenido visual de los libros de texto respecto a la cultura corporal y a la edad con la finalidad de desvelar y velar por su coherencia con la corriente pedagógica e ideológica de los entes reguladores de la educación de Brasil.

\section{ESTEREOTIPOS SOCIALES VINCULADOS A LA EDAD}

Los estereotipos etarios y relacionados con la discapacidad han sido objeto de menos investigaciones que los relacionados con el género ${ }^{1}$ y la raza. Además la literatura

1 El género es conceptualizado como un elemento constitutivo prioritario de las relaciones sociales entre los sexos. El género es una simbolización de la diferencia sexual que ejerce un papel fundamental en la organización y distribución del poder (Scott, 1986). Lo femenino y masculino, lejos de ser una realidad binaria asociada esencialmente a cada sexo, es "la mejor fundada de las ilusiones colectivas" que actúa imponiendo atribuciones a cada sexo y colabora a una interesada distribución del poder (Bourdieu, 2008, p. 232). 
revisada sugiere que los pocos estudios existentes sobre la edad se centran más en los estereotipos pertenecientes a las personas mayores que en el resto de franjas etarias. $\mathrm{El}$ envejecimiento es percibido como un proceso de deterioro creciente (Gazquez et al., 2009) y los estereotipos se han generalizado hacia valoraciones negativas de la vejez (Carbajo, 2009). La imagen de las personas mayores es definida hoy en día por características negativas tanto físicas, como sociales o psicológicas: incapaces, enfermas, lentas, introvertidas, depresivas, rígidas, inactivas, incompetentes o pasivas (Carbajo, 2009; Fernández,2003). Muchas personas jóvenes asimilan estos estereotipos y acaban percibiendo a las personas mayores como menos capaces para participar en las mismas actividades que ellos (Robinson et al., 2007). En contraposición, las instituciones actuales insisten en que los "adultos mayores" representan un grupo social específico y heterogéneo, por lo que no pueden ser identificados y clasificados exclusivamente de acuerdo con su edad, ya que representan experiencias, actitudes e intereses diversos (Ivic, 2013). Las limitaciones, deficiencias y dificultades no son solo problemas de los ancianos. Hay muchos niños y niñas, adolescentes, jóvenes y personas adultas que poseen dificultades debido a diversas causas patológicas (Scortegagna y Oliveira, 2012).

\section{HÁBITOS SALUDABLES, EDUCACIÓN FÍSICA Y EDAD}

La educación física escolar aborda en sus contenidos las diferentes prácticas corporales. Estas son definidas como un conjunto de diferentes actividades corporales vinculadas al desarrollo de una dinámica motriz que tiene por finalidad la expresión lúdica, y/o la mejora de la salud y de la sensibilidad (Lazzarotti Filho et al., 2010). Un tipo de prácticas corporales son los deportes, hegemónicos en la cultura corporal moderna (Taffarel, 2000). Pero existen otras expresiones motrices como los juegos, los sistemas gimnásticos, las danzas, las actividades introyectivas, las actividades artístico-expresivas, el circo, la capoeira, las luchas, etc. Cada modalidad de práctica corporal representa valores y principios culturales, por lo que deben ser tratadas en la educación física con la conciencia de que actúan sobre la sociedad en la que el cuerpo está inserto (Daolio, 1995).

Mosquera y Puig (2002) defienden que las diferencias de participación en prácticas corporales observadas en el pasado entre jóvenes y mayores no se deben a razones de orden biológico, sino estrictamente de carácter generacional. Moscoso y Martín (2009) apuntan que la transmisión de valores de cultura deportiva relacionados con la edad es un factor determinante en la práctica de actividad física-deportiva. La participación de los diferentes grupos de edad en las prácticas corporales estará influenciada por las creencias que se transmiten sobre ellos (Táboas, 2009).

$\mathrm{El}$ habitus arraigado en la educación física se apoya en la ejercitación para el mantenimiento de una figura sana y atractiva, con una especial atención a las dimensiones y potenciales biológicos del cuerpo (Daolio, 1995; Silva et al., 2009). El cuerpo es "un proyecto personal que puede ser controlado gracias a los avances de expertos, tecnólogos y científicos de diversa índole" (Muñoz, 2007, p. 10) y por lo tanto "la apariencia externa pone de manifiesto el código moral del individuo"(Barbero, 2005, p. 47). En línea a esta disposición generalizada en la educación física "los jóvenes, sobre todo, poseen el cuerpo como una especie de capital físico que hay que explotar y lo convierten 
en objeto de construcción y trabajo"(Vázquez, 2001,p.14). Ese esquema provoca que las personas mayores hayan quedado al margen de este campo. La investigación realizada por Gómes da Silva, Imbiriba y Lüdorf (2015) con profesorado de educación física de Río de Janeiro reveló que el enfoque de la salud desplegado se sustenta en gran medida en una racionalidad antropológica de la discriminación (Moreno, 2013). El cuerpo saludable se equipara a un cuerpo ideal y se propone como la expresión más elevada de las virtudes físicas y morales, mientras que el cuerpo deficitario, incluido el cuerpo envejecido, exhibe taras y defectos que marcan el límite de lo inhumano.

No se han encontrado estudios sobre los hábitos de práctica corporal de las personas mayores en Brasil, pero estudios efectuados en España arrojan que solo dos de cada 10 personas mayores de 65 años practican deporte, pero al menos seis de cada 10 pasean habitualmente (Moscoso y Moyano, 2009). La discriminación y los estereotipos que afectan a las personas mayores en el campo del ejercicio físico y el deporte están determinados porque es un espacio social en el que se expresan las lógicas de sujeción de los cuerpos a la disciplina de los mecanismos normalizadores del sistema capitalista (Rey-Cao, Táboas-Pais y Canales-Lacruz, 2013).

No obstante, las personas mayores en las sociedades del capitalismo tardío se transforman también en consumidoras de mercado y en responsables del control de sus cuerpos (Bauman, 2000). La demanda de nuevos estilos de vida para la población en envejecimiento y la promesa de una vida larga se apoya en el cambio del valor "salud" por el de "buena forma" (Magaly, 2011). De este modo se incrementa la presencia de valores que enfatizan la necesidad de que las personas mayores mantengan un cuidado personal, tengan hábitos saludables de vida y disfruten del tiempo libre (Rey-Cao, Táboas-Pais y Canales-Lacruz, 2013).

El análisis realizado por Becerril (2011) sobre las portadas de la revista "60 y más”, publicada por el Instituto de Mayores y Servicios Sociales (IMSERSO) en España reveló que las personas protagonistas de las portadas pertenecían a la primera franja de edad - 60-75 años - con una figura propia de un cuerpo de tipo atlético, delgado y de aspecto ágil, estaban ubicadas en espacios exteriores - parques, jardines, playa...-, y en ámbitos de educación no formal e informal. Las actividades más representadas en esas imágenes fueron los juegos de pelota, los paseos y el baile.

\section{REPRESENTACIÓN DE LA EDAD EN LAS IMÁGENES DE LOS LIBROS DE TEXTO}

La representación de la edad en los libros de texto está sesgada y caracterizada por la invisibilización de las personas mayores. El análisis realizado por Oliveira (2008) sobre 28 libros de lengua extranjera brasileños mostró que la edad más representada era la comprendida entre los 30 y 40 años, y que las personas ancianas aparecían ejerciendo el papel de abuelos o abuelas, sentadas en un banco en la plaza, o durmiendo frente a la televisión. Según Blanco (2003) la edad adulta es la más frecuente en los materiales didácticos españoles, seguida de la juventud, mientras que el grupo de edad de personas mayores está prácticamente ausente en los textos escolares. Torres (2008) también manifiesta que la edad adulta es la 
"voz presente" en los libros de texto españoles mientras que la infancia, la juventud y la tercera edad son las "voces ausentes". El análisis de contenido realizado por Martínez (2013) sobre 1128 imágenes de 6 editoriales pertenecientes al área de Conocimiento del Medio Natural, Social y Cultural, encontró que en la representación de la edad el 63\% eran niños o niñas, el 29\% personas adultas, el 4\% jóvenes y el $3 \%$ personas adultas mayores.

Botelho y Neira (2014), en su revisión de los trabajos que se centran en el análisis de los libros de texto de educación física en Brasil y España, mencionan un trabajo de Silveira del año 2000 en el que encontró que de un total de 58 ilustraciones, dos hacían referencia a las actividades físicas, 52 presentaban niños y adolescentes, y las ocho restantes eran imágenes de adultos. No había ninguna imagen de personas mayores. El análisis de los libros de texto de educación física españoles (Táboas, 2009) mostró que el colectivo de niños/adolescentes era el más representado (48,63\%), y el siguiente grupo era el de jóvenes (38,62\%). Las personas adultas y las personas mayores eran las menos representadas (3,93\% y 1,01\%, respectivamente). El colectivo de jóvenes era el más representado en 7 de las 10 editoriales analizadas.

Un estudio realizado por Rey-Cao, Táboas-Pais y Canales-Lacruz (2013) sobre la representación de las personas mayores en las imágenes de los libros de texto de educación física españoles dirigidos a la etapa de secundaria — de 12 a 16 años reveló que tan solo el 1,4\% - porcentaje que engloba imágenes en las que aparecen tanto personas mayores solas como con otros colectivos de edad - representan a este colectivo. En relación al análisis del sexo de las personas mayores, los datos evidenciaron la invisibilidad de las mujeres mayores en estos manuales. El análisis semiótico de las imágenes de los libros de educación física indicó que las imágenes de personas mayores fueron tomadas desde un enfoque medio en el $60,7 \%$ de los casos y que el número de imágenes tomadas desde enfoques picados era significativamente mayor que desde enfoques contrapicados. Las personas mayores aparecían practicando juegos tradicionales en un 39,4\%, deportes individuales en un 27,3\%, y actividades de la vida diaria en un 15,2\% de los casos.Las imágenes de personas mayores se ubicaban en ámbitos de carácter recreativo en el 73,91\% de los casos, el 13,4\% en el ámbito competitivo y el 13,4\% en el ámbito utilitario. En el 73,3\% de los casos las personas mayores utilizaban espacios no deportivos, y en el 81,8\% de las imágenes en las que aparecían personas mayores se representaban actividades que no eran de práctica corporal de élite.

Los análisis de los libros de texto y su comparación con las finalidades del sistema educativo y con el contexto jurídico español han permitido formular recomendaciones específicas al respecto de la representación de la edad: representar a personas de edades diversas y en convivencia intergeneracional; evitar la representación excesiva de una franja etaria asociada a una determinada actividad físico-deportiva, ámbito o espacio; incorporar imágenes de personas adultas y personas mayores de ambos géneros participando en una amplia variedad de actividades físico-deportivas; evitar la invisibilización y estereotipación de las personas mayores, especialmente de las mujeres mayores; y evitar las representaciones ejemplares polarizadas - entre personas mayores "juveniles y hedonistas" o "fragilizadas y dependientes" - , porque pueden legitimarse como los únicos roles en los que las personas mayores merecen ser visibilizadas socialmente (Rey-Cao y González-Palomares, 2014). 
Los estudios previos mencionados permiten anticipar las siguientes hipótesis sobre las imágenes de los libros de texto de educación física de Brasil:

- Niños y niñas, personas adolescentes y personas jóvenes son las más representadas; mientras que personas adultas y personas mayores son menos representadas;

- La representación de mujeres mayores es muy inferior a la de hombres mayores;

- La mayoría de personas mayores se representa con un enfoque medio, practicando deportes individuales y juegos tradicionales en ámbitos de carácter recreativo, espacios no deportivos y en niveles de práctica no vinculados a la élite.

Además el estudio pretende recoger información para responder a los siguientes objetivos que no han sido suficientemente abordados en la literatura:

- Analizar cómo es la representación de las personas en los libros de texto en función de la edad con respecto al tipo de enfoque y el género;

- Describir el ámbito, el espacio, el nivel y los tipos de prácticas corporales que se representan en los libros de texto en función de la edad.

\section{METODOLOGÍA}

\section{MUESTRA}

El diseño muestral fue de carácter no probabilístico. La selección de la muestra fue intencional o de conveniencia. Se analizaron libros destinados al alumnado de la enseñanza fundamental y media publicados entre los años 2006 y 2012. Se observaron 929 fotografías pertenecientes a 36 libros de texto de educación física publicados en Brasil en los estados de Paraíba (PB), Paraná (PR), Rio Grande do Sul (RS) y São Paulo (SP); y la editorial Ícone (IC) (Cuadro 1).

Cuadro 1 - Libros de texto de educación física de Brasil

\begin{tabular}{|l|c|c|c|c|}
\hline Estado & Libro didáctico & Año & Nivel escolar & Imágenes \\
\hline PB & $\begin{array}{c}\text { Livro didático público } \\
\text { do Paraíba }\end{array}$ & 2012 & Enseñanza fundamental & 65 \\
\hline PR & $\begin{array}{c}\text { Livro didático público } \\
\text { do Paraná }\end{array}$ & 2007 & Enseñanza media & 27 \\
\hline RS & $\begin{array}{c}\text { Lições do Rio Grande } \\
\text { Referenciais Curriculares }- \\
\text { Caderno do aluno }\end{array}$ & 2009 & Enseñanza fundamental & 111 \\
\hline SP & Cadernos do aluno & 2010 & $\begin{array}{c}\text { Enseñanza } \\
\text { fundamental y media }\end{array}$ & 375 \\
\hline IC & $\begin{array}{c}\text { Coleção Cultura Corporal } \\
\text { (Quatro volumeis) }\end{array}$ & $\begin{array}{c}2008- \\
2011\end{array}$ & $\begin{array}{c}\text { Enseñanza } \\
\text { fundamental y media }\end{array}$ & 351 \\
\hline
\end{tabular}

Fuente: resultados de la investigación.

Elaborado por las autoras. 


\section{VARIABLES}

La recogida de datos se hizo mediante análisis de contenido. Este método es utilizado para la captación sistemática e interpretación del contenido de las imágenes (Heinemann, 2003) y permite desvelar lo oculto o disimulado en el mensaje.

Las variables que se analizaron fueron: edad, sexo, tipo de práctica corporal, ámbito de práctica, espacio y nivel.

Las imágenes fueron codificadas por edad - apariencia de las personas con relación a la edad cronológica y biológica, y también con respecto a la construcción social que se deriva de esa apariencia —; sexo — condiciones de la apariencia de las personas protagonistas de la imagen que permiten establecer unas diferencias biológicas entre hombres, mujeres y grupos de hombres-mujeres —; tipo de práctica corporal — las diferentes denominaciones de las prácticas corporales y/o deportes -; ámbito de práctica - contexto o situación donde se realiza la actividad —; espacio -entorno físico donde se practica la actividad —; y nivel — nivel de dedicación, seriedad y/o profesionalización - L La variable independiente de este estudio es la edad.

En el Cuadro 2 se explicitan las definiciones de los indicadores que operativizan cada una de las variables y que se aplicaron en el instrumento de análisis de contenido.

\section{PROCEDIMIENTO}

El instrumento de observación empleado es una adaptación del propuesto por Táboas (2009). La adaptación se ejecutó en 3 fases, que se corresponden con los controles a los que debe ser sometido un instrumento para demostrar su validez, fiabilidad, objetividad y utilidad práctica (Heinemann, 2003).

1. Prueba piloto. El objetivo fue valorar la validez de la herramienta tras los cambios efectuados en la categoría ámbito de práctica, que fue reelaborada ad hoc para esta investigación. Se codificó una muestra de 238 imágenes que no pertenecían a la muestra final analizada seleccionadas mediante un muestreo aleatorio simple;

2. Consulta a expertos/as. Se solicitó a tres personas expertas en análisis de contenido su opinión sobre: adecuación del sistema de categorías al objeto de estudio, exhaustividad y mutua exclusividad de las categorías, claridad en la redacción de las definiciones y minimización de la subjetividad del observador. La información se recogió mediante escala de Likert con valores comprendidos entre 1 - muy en desacuerdo - y 5 - muy de acuerdo - e información cualitativa complementaria. Las tres personas expertas valoraron la mayoría de los ítems con un 4 ó 5;

3. Prueba intercodificadores. Colaboraron en esta tarea de validación tres expertas en análisis de contenido. La observación y codificación de las imágenes se realizó de forma individual con 50 imágenes. El criterio de selección fue que saturasen la codificación de todos los indicadores del sistema. Se calculó la fiabilidad intercodificadores para averiguar el grado de acuerdo. Los valores del alfa de Krippendorff $(>0,80)$ obtenidos 


\section{Cuadro 2 - Sistema de categorías}

\begin{tabular}{|c|c|c|}
\hline Dimensiones & Categorías & Indicadores \\
\hline \multirow{3}{*}{$\begin{array}{l}\text { 0. Características } \\
\text { técnicas }\end{array}$} & \multirow{3}{*}{ Tipo de enfoque } & 0.1.1. Picado \\
\hline & & 0.1.2. Contrapicado \\
\hline & & 0.1.3. Medio \\
\hline \multirow{10}{*}{ 1. Cuerpo } & \multirow{4}{*}{ 1.1. Sexo } & 1.1.1. Hombres \\
\hline & & 1.1.2. Mujeres \\
\hline & & 1.1.3. Grupos de hombres-mujeres \\
\hline & & 1.1.4. No se distingue \\
\hline & \multirow{6}{*}{ 1.2. Edad } & 1.2.1. Niño-a/adolescente \\
\hline & & 1.2.2. Joven \\
\hline & & 1.2.3. Adulto-a \\
\hline & & 1.2.4. Persona mayor \\
\hline & & 1.2.5. Varios \\
\hline & & 1.2.6. No se distingue \\
\hline \multirow{30}{*}{ 2. Práctica corporal } & \multirow{13}{*}{ 2.1. Tipo de práctica corporal } & 2.1.1. Deportes colectivos \\
\hline & & 2.1.2. Deportes individuales \\
\hline & & 2.1.3. Artísticas \\
\hline & & 2.1.4. Fitness y condición física \\
\hline & & 2.1.5. Complementarias \\
\hline & & 2.1.6. De higiene postural \\
\hline & & $\begin{array}{l}\text { 2.1.7. Actividades Físicas de Aventura } \\
\text { en la Naturaleza (AFAN) }\end{array}$ \\
\hline & & 2.1.8. Prácticas de interiorización \\
\hline & & 2.1.9. Juegos \\
\hline & & 2.1.10. Laborales \\
\hline & & 2.1.11. Actividades de la Vida Diaria (AVD) \\
\hline & & 2.1.12. Otras \\
\hline & & 2.1.13. No se distingue \\
\hline & \multirow{8}{*}{ 2.2. Ámbito de práctica } & 2.2.1. Competitivo \\
\hline & & 2.2.2. Educativo formal \\
\hline & & 2.2.3. Educativo no formal \\
\hline & & 2.2.4. Informal \\
\hline & & 2.2.5. Utilitario \\
\hline & & 2.2.6. Instrumentalizado \\
\hline & & 2.2.7. Escénico \\
\hline & & 2.2.8. No se distingue \\
\hline & \multirow{6}{*}{ 2.3. Espacio } & 2.3.1. Exterior deportivo \\
\hline & & 2.3.2. Medio natural \\
\hline & & 2.3.3. Exterior \\
\hline & & 2.3.4. Interior deportivo \\
\hline & & 2.3.5. Interior \\
\hline & & 2.3.6. No se distingue \\
\hline & \multirow{3}{*}{ 2.4. Nivel } & 2.4.1. Élite \\
\hline & & 2.4.2. No élite \\
\hline & & 2.4.3. No se distingue \\
\hline
\end{tabular}

Fuente: resultados de la investigación.

Elaborado por las autoras. 
en todas la variables confirman la fiabilidad del sistema de categorías. Finalizada la codificación de todas las imágenes, una persona externa a este proceso codificó el 10\% de la muestra (93 imágenes) y se calculó nuevamente el alfa de Krippendorff para averiguar la fiabilidad de la codificación final. Para esta segunda prueba de fiabilidad se llevó a cabo un muestreo aleatorio simple para la selección de las imágenes. El alfa de Krippendorff calculado en esta segunda prueba obtuvo valores superiores al mínimo establecido $(>0,80)$ y confirmó la fiabilidad de los resultados.

\section{ANÁLISIS Y PROCESAMIENTO DE LOS DATOS}

Las imágenes se analizaron mediante observación directa del libro de texto. Aquellas fotografías que presentaron dudas acerca del tipo de práctica corporal representado en la imagen se codificaron a través de la información aportada por el texto o paratexto que las acompañaba. El análisis estadístico se llevó a cabo con la ayuda del software SPSS 19.0. Se realizó un análisis descriptivo uni-variante y medidas de asociación entre las diferentes variables — bi-variante - Se emplearon tablas de contingencia y residuos tipificados corregidos y se aplicó el test Ji-cuadrado de Pearson con un nivel de significación en el 5\% $(\alpha=0,05)$.

\section{RESULTADOS}

Hipótesis 1: Los niños y niñas, las personas adolescentes y las personas jóvenes son las más representadas; mientras que las personas adultas y las personas mayores son las menos representadas.

Para la categorización de la variable edad existen 229 casos perdidos, que se corresponden con aquellas imágenes en las que no es posible distinguir la franja etaria de los sujetos. Por lo tanto, para la descripción de dicha variable $n=700$. La franja etaria más representada en las imágenes de los libros de texto de educación física es la de niño-a/adolescente con un total de 331 imágenes (47,3\% del total). E1 siguiente colectivo es el de jóvenes, representado en 193 imágenes (27,6\%). Un total de 118 imágenes (16,9\%) muestran personas de diferentes franjas etarias realizando prácticas corporales de forma conjunta. El cuarto grupo de edad se corresponde con las personas adultas, representadas en 48 imágenes (6,9\%). Las personas mayores, con un total de 10 imágenes (1,4\%), son las menos representadas. En el análisis de los libros de los estados y de la editorial privada se observan diferencias en la representación de los diferentes grupos de edad. Los estados de PB y de RS no presentan imágenes de personas adultas en sus libros. El estado de $\mathrm{PR}$ no representa imágenes de niñez/adolescencia. El estado de SP y la editorial IC representan todas las franjas etarias, pero con grandes diferencias en los porcentajes de cada una de ellas (Tabla 1). El análisis reveló que el indicador más frecuente en 3 de las 5 propuestas curriculares es el de joven.

Hipótesis 2: La representación de las mujeres mayores es muy inferior a la de los hombres mayores. 
Los resultados de este cruce se obtuvieron de una muestra de 687 fotografías ( $n=687)$. Existieron 242 casos perdidos. De las 8 fotografías en las que aparecen personas mayores y en las que es posible identificar su sexo, 3 imágenes muestran hombres (37,5\%); 3 imágenes muestran mujeres (37,5\%); y 2 imágenes muestran hombres y mujeres juntos (25\%).

$\mathrm{El}$ análisis de la representación de los diferentes grupos de edad con respecto al género mostró que el indicador niño-aladolescente se distribuye en 64 imágenes de hombres (19,9\%); 92 imágenes de mujeres (28,6\%); y 166 imágenes de grupos mixtos (51,6\%). El indicador joven se distribuye en 112 imágenes de hombres (58\%); en 55 de mujeres (28,5\%); y en 26 de hombres y mujeres (13,5\%). El indicador adultola muestra 38 imágenes de hombres (79,5\%); 6 de mujeres (12,5\%); y 4 de grupos mixtos (8,3\%). El cálculo de los residuos tipificados corregidos confirmó que la relación entre las variables sexo-agrupación y edad es estadísticamente significativa. La probabilidad de que las personas jóvenes y adultas sean hombres (residuo 7,6 y 6,5 respectivamente) o de que los niños-as/adolescentes sean mujeres (residuo 2,4) o grupos mixtos (residuo 5,9) fue significativamente mayor de lo que cabría esperar si las variables fueran independientes.

Hipótesis 3: La mayoría de las personas mayores se representa con un enfoque medio, practicando deportes individuales y juegos tradicionales en ámbitos de carácter recreativo, espacios no deportivos y en niveles de práctica no vinculadas a la élite.

Los resultados del cruce tipo de enfoque y edad fueron obtenidos a partir de una muestra de 701 fotografías ( $n=701$ ). Existieron 228 casos perdidos. De las 10 imágenes

Tabla 1 - Imágenes de los diferentes grupos etarios en los libros de texto de educación física

\begin{tabular}{|c|c|c|c|c|c|c|c|}
\hline \multirow{2}{*}{\multicolumn{2}{|c|}{ Estado }} & \multicolumn{5}{|c|}{ EDAD } & \multirow{3}{*}{$\begin{array}{c}\text { Total } \\
60 \\
100 \% \\
\end{array}$} \\
\hline & & \multirow{2}{*}{$\begin{array}{c}\text { Niño/a- } \\
\text { adolescente } \\
43 \\
71,7 \% \\
\end{array}$} & \multirow{2}{*}{$\begin{array}{c}\text { Joven } \\
11 \\
18,3 \% \\
\end{array}$} & \multirow{2}{*}{$\begin{array}{c}\text { Adulto/a } \\
0 \\
0 \%\end{array}$} & \multirow{2}{*}{$\begin{array}{c}\text { Persona } \\
\text { mayor }\end{array}$} & \multirow{2}{*}{\begin{tabular}{|c|} 
Varios \\
4 \\
$6,7 \%$ \\
\end{tabular}} & \\
\hline $\mathrm{PB}$ & $\begin{array}{c}\text { Recuento } \\
\%\end{array}$ & & & & & & \\
\hline PR & $\begin{array}{c}\text { Recuento } \\
\%\end{array}$ & $\begin{array}{c}0 \\
0 \%\end{array}$ & $\begin{array}{c}8 \\
61,5 \% \\
\end{array}$ & $\begin{array}{c}1 \\
7,7 \%\end{array}$ & $\begin{array}{c}1 \\
7,7 \% \\
\end{array}$ & $\begin{array}{c}3 \\
23,1 \% \\
\end{array}$ & $\begin{array}{c}13 \\
100 \%\end{array}$ \\
\hline SP & $\begin{array}{c}\text { Recuento } \\
\%\end{array}$ & $\begin{array}{c}74 \\
32,3 \% \\
\end{array}$ & $\begin{array}{c}98 \\
42,8 \% \\
\end{array}$ & $\begin{array}{c}32 \\
14 \%\end{array}$ & $\begin{array}{c}3 \\
1,3 \% \\
\end{array}$ & $\begin{array}{c}22 \\
9,6 \%\end{array}$ & $\begin{array}{c}229 \\
100 \%\end{array}$ \\
\hline RS & $\begin{array}{c}\text { Recuento } \\
\%\end{array}$ & $\begin{array}{c}10 \\
20 \% \\
\end{array}$ & $\begin{array}{c}32 \\
64 \% \\
\end{array}$ & $\begin{array}{c}0 \\
0 \% \\
\end{array}$ & $\begin{array}{c}2 \\
4 \% \\
\end{array}$ & $\begin{array}{c}6 \\
12 \% \\
\end{array}$ & $\begin{array}{c}50 \\
100 \% \\
\end{array}$ \\
\hline IC & $\begin{array}{c}\text { Recuento } \\
\%\end{array}$ & $\begin{array}{c}204 \\
58,6 \% \\
\end{array}$ & $\begin{array}{c}44 \\
12,6 \% \\
\end{array}$ & $\begin{array}{c}15 \\
4,3 \%\end{array}$ & $\begin{array}{c}2 \\
0,6 \% \\
\end{array}$ & $\begin{array}{c}83 \\
23,9 \% \\
\end{array}$ & $\begin{array}{c}348 \\
100 \% \\
\end{array}$ \\
\hline Total & $\begin{array}{c}\text { Recuento } \\
\%\end{array}$ & $\begin{array}{c}331 \\
47,3 \%\end{array}$ & $\begin{array}{c}193 \\
27,6 \%\end{array}$ & $\begin{array}{c}48 \\
6,9 \%\end{array}$ & $\begin{array}{c}10 \\
1,4 \%\end{array}$ & $\begin{array}{c}118 \\
16,9 \%\end{array}$ & $\begin{array}{c}700 \\
100 \%\end{array}$ \\
\hline
\end{tabular}

Fuente: resultados de la investigación.

Elaborado por las autoras. 
que presentan personas mayores, 6 imágenes (60\%) se corresponden con un enfoque medio, es decir, con una utilización neutra de la cámara. De las 4 restantes, 3 fotografías (30\%) presentan un enfoque contrapicado, que aporta a las personas un aire de importancia, poder y confianza. Por el contrario, 1 imagen (10\%) presenta un enfoque picado, en el que la persona adquiere un aspecto más débil y menos importante. $\mathrm{El}$ resto de edades también son fotografiadas mayoritariamente con un enfoque medio. El cálculo de los residuos tipificados corregidos confirmó que la relación entre las variables tipo de enfoque y edad es estadísticamente significativa. La probabilidad de que las personas jóvenes sean fotografiadas con un enfoque contrapicado fue significativamente mayor de lo que cabría esperar si las variables fueran independientes (residuo 6,2). Por el contrario, la probabilidad de que el colectivo niños-as/adolescentes sea fotografiado con un enfoque contrapicado (residuo -4,8) fue significativamente menor de lo que cabría esperar si las variables fueran independientes.

Para el cruce tipo de práctica corporal y edad el valor de $n$ fue de 699. Existieron 230 casos perdidos. La práctica corporal más realizada por las personas mayores son las actividades artísticas, correspondiéndose con 3 imágenes del total (30\%). Las siguientes prácticas son los juegos (20\%) y las otras actividades (20\%), con 2 imágenes cada indicador. Las prácticas corporales más realizas por los niños/as-adolescentes son los deportes individuales con 71 imágenes (21,5\%). Le siguen las actividades artísticas con 62 imágenes (18,8\%) y los juegos con 52 imágenes $(15,8 \%)$. Los jóvenes practican en 59 imágenes (30,6\%), deportes individuales; en 50 imágenes (25,9\%), deportes colectivos; y en 48 imágenes (24,9\%) actividades artísticas. Se observa que las personas jóvenes se relacionan mayoritariamente con los deportes, tanto individuales como colectivos. El grupo de las personas adultas practica mayoritariamente deportes individuales. Esto se corresponde con 25 imágenes (52,1\% del total). Las siguientes prácticas que realiza este colectivo son las actividades artísticas en 8 imágenes $(16,7 \%)$ y las actividades de fitness y condición física en 4 imágenes (8,3\%). Las prácticas más realizadas de forma conjunta por grupos intergeneracionales son: los deportes individuales, con 53 imágenes (44,9\%); las actividades artísticas, con 24 casos (20,3\%); y los juegos, con 12 imágenes (10,2\%). (Tabla 2).

En el Gráfico 1 se pueden observar las distribuciones de las diferentes prácticas corporales en función de los distintos grupos de edad.

Los resultados para el cruce ámbito-edad se obtuvieron de una muestra de 574 fotografías $(n=574)$. Existieron 355 casos perdidos. De las 10 imágenes que representan personas mayores, 4 fotografías (40\%) se ubican en el ámbito educativo no formal; en los ámbitos informal y escénico se encontraron 2 imágenes (20\%) respectivamente. Por lo que el $80 \%$ de las imágenes de personas mayores se ubica en ámbitos de carácter recreativo. El 20\% restante se corresponde con una imagen en el ámbito competitivo y otra en el ámbito utilitario. Con relación a las otras franjas etarias, el ámbito en el que más se representa al colectivo de niños/as-adolescentes es el educativo formal con 182 imágenes (66,7\%); el ámbito en el que se ubican las personas jóvenes es el competitivo con 67 fotografías (44,1\%); los ámbitos en los que son representados las personas adultas son el informal con 7 imágenes $(29,2 \%)$ y el utilitario con 6 (25\%). Los diferentes grupos de edad se ubican con 46 imágenes (40\%) en el ámbito educativo no formal (Gráfico 2). 
Los porcentajes de los resultados para el cruce espacio-edad se obtienen de $n=615$. Hay 314 casos perdidos. Las personas mayores se representan en espacios no deportivos en 8 imágenes (80\%). En los otros 2 casos (20\%) se ubican en espacios deportivos como un pabellón o un campo de croquet. El análisis descriptivo de los otros colectivos reveló que el colectivo de niños-as/adolescentes, las personas adultas y las imágenes que representan diferentes franjas de edad practicando la misma práctica corporal se ubican en espacios no deportivos con un 77,2\% $(n=231)$, un $83,4 \%(n=20)$ y un $77,4 \%(n=89)$, respectivamente. Por el contrario, las personas jóvenes se representan en un 57,4\% ( $n=96)$ en espacios deportivos (Tabla 3). El cálculo de los residuos tipificados corregidos confirmó que la relación entre las variables espacio y edad es estadísticamente significativa. La probabilidad de que las personas jóvenes aparezcan representadas en espacios deportivos (residuo 8,3) y que las personas que son niños/as-adolescentes aparezcan ubicadas en espacios no deportivos

Tabla 2 - Imágenes de los diferentes grupos etarios en función del tipo de práctica corporal

\begin{tabular}{|c|c|c|c|c|c|c|}
\hline \multirow{2}{*}{\multicolumn{2}{|c|}{$\begin{array}{l}\text { Tipo de práctica } \\
\text { corporal }\end{array}$}} & \multicolumn{5}{|c|}{ EDAD } \\
\hline & & \multirow{2}{*}{$\begin{array}{c}\text { Niño/a- } \\
\text { Adolescente }\end{array}$} & \multirow{2}{*}{$\begin{array}{c}\text { Joven } \\
50 \\
25,9 \% \\
\end{array}$} & \multirow{2}{*}{$\begin{array}{c}\text { Adulto/a } \\
1 \\
2,1 \%\end{array}$} & \multirow{2}{*}{$\begin{array}{c}\text { Persona } \\
\text { mayor }\end{array}$} & \multirow{2}{*}{$\begin{array}{c}\text { Varios } \\
8 \\
6,8 \%\end{array}$} \\
\hline $\begin{array}{l}\text { Deportes } \\
\text { colectivos }\end{array}$ & $\begin{array}{c}\text { Recuento } \\
\%\end{array}$ & & & & & \\
\hline $\begin{array}{l}\text { Deportes } \\
\text { individuales }\end{array}$ & $\begin{array}{c}\text { Recuento } \\
\%\end{array}$ & $\begin{array}{c}71 \\
21,5 \%\end{array}$ & $\begin{array}{c}59 \\
30,6 \%\end{array}$ & $\begin{array}{c}25 \\
52,1 \%\end{array}$ & $\begin{array}{c}1 \\
10 \%\end{array}$ & $\begin{array}{c}53 \\
44,9 \%\end{array}$ \\
\hline $\begin{array}{l}\text { Actividades } \\
\text { artísticas }\end{array}$ & $\begin{array}{c}\text { Recuento } \\
\%\end{array}$ & $\begin{array}{c}62 \\
18,8 \%\end{array}$ & $\begin{array}{c}48 \\
24,9 \%\end{array}$ & $\begin{array}{c}8 \\
16,7 \%\end{array}$ & $\begin{array}{c}3 \\
30 \%\end{array}$ & $\begin{array}{c}24 \\
20,3 \%\end{array}$ \\
\hline $\begin{array}{l}\text { Fitness y } \\
\text { condición física }\end{array}$ & $\begin{array}{c}\text { Recuento } \\
\%\end{array}$ & $\begin{array}{c}47 \\
14,2 \%\end{array}$ & $\begin{array}{c}13 \\
6,7 \%\end{array}$ & $\begin{array}{c}4 \\
8,3 \%\end{array}$ & $\begin{array}{c}0 \\
0 \%\end{array}$ & $\begin{array}{c}5 \\
4,2 \%\end{array}$ \\
\hline $\begin{array}{l}\text { Actividades } \\
\text { complementarias }\end{array}$ & $\begin{array}{c}\text { Recuento } \\
\%\end{array}$ & $\begin{array}{c}0 \\
0 \%\end{array}$ & $\begin{array}{c}1 \\
0,5 \%\end{array}$ & $\begin{array}{c}0 \\
0 \%\end{array}$ & $\begin{array}{c}0 \\
0 \%\end{array}$ & $\begin{array}{c}0 \\
0 \%\end{array}$ \\
\hline $\begin{array}{l}\text { Prácticas de } \\
\text { interiorización }\end{array}$ & $\begin{array}{c}\text { Recuento } \\
\%\end{array}$ & $\begin{array}{c}34 \\
10,3 \%\end{array}$ & $\begin{array}{c}7 \\
3,6 \% \\
\end{array}$ & $\begin{array}{c}2 \\
4,2 \% \\
\end{array}$ & $\begin{array}{c}1 \\
10 \%\end{array}$ & $\begin{array}{c}1 \\
0,8 \%\end{array}$ \\
\hline Juegos & $\begin{array}{c}\text { Recuento } \\
\%\end{array}$ & $\begin{array}{c}52 \\
15,8 \% \\
\end{array}$ & $\begin{array}{c}2 \\
1 \%\end{array}$ & $\begin{array}{c}2 \\
4,2 \% \\
\end{array}$ & $\begin{array}{c}2 \\
20 \%\end{array}$ & $\begin{array}{c}12 \\
10,2 \%\end{array}$ \\
\hline Laborales & $\begin{array}{c}\text { Recuento } \\
\%\end{array}$ & $\begin{array}{c}1 \\
0,3 \%\end{array}$ & $\begin{array}{c}0 \\
0 \%\end{array}$ & $\begin{array}{c}2 \\
4,2 \%\end{array}$ & $\begin{array}{c}1 \\
10 \%\end{array}$ & $\begin{array}{c}2 \\
1,7 \%\end{array}$ \\
\hline $\begin{array}{l}\text { Actividades de } \\
\text { la Vida Diaria }\end{array}$ & $\begin{array}{c}\text { Recuento } \\
\%\end{array}$ & $\begin{array}{c}14 \\
4,2 \% \\
\end{array}$ & $\begin{array}{c}4 \\
2,1 \% \\
\end{array}$ & $\begin{array}{c}3 \\
6,2 \% \\
\end{array}$ & $\begin{array}{c}0 \\
0 \% \\
\end{array}$ & $\begin{array}{c}5 \\
4,2 \% \\
\end{array}$ \\
\hline Otras & $\begin{array}{c}\text { Recuento } \\
\%\end{array}$ & $\begin{array}{c}11 \\
3,3 \%\end{array}$ & $\begin{array}{c}9 \\
4,7 \%\end{array}$ & $\begin{array}{c}1 \\
2,1 \%\end{array}$ & $\begin{array}{c}2 \\
20 \%\end{array}$ & $\begin{array}{c}8 \\
6,8 \%\end{array}$ \\
\hline Total & $\begin{array}{c}\text { Recuento } \\
\%\end{array}$ & $\begin{array}{c}330 \\
100 \%\end{array}$ & $\begin{array}{c}193 \\
110 \%\end{array}$ & $\begin{array}{c}48 \\
100 \%\end{array}$ & $\begin{array}{c}10 \\
100 \%\end{array}$ & $\begin{array}{c}118 \\
100 \%\end{array}$ \\
\hline
\end{tabular}

Fuente: resultados de la investigación.

Elaborado por las autoras. 
Gráfico 1 - Prácticas corporales representadas en las imágenes de los libros de texto de educación física según la edad

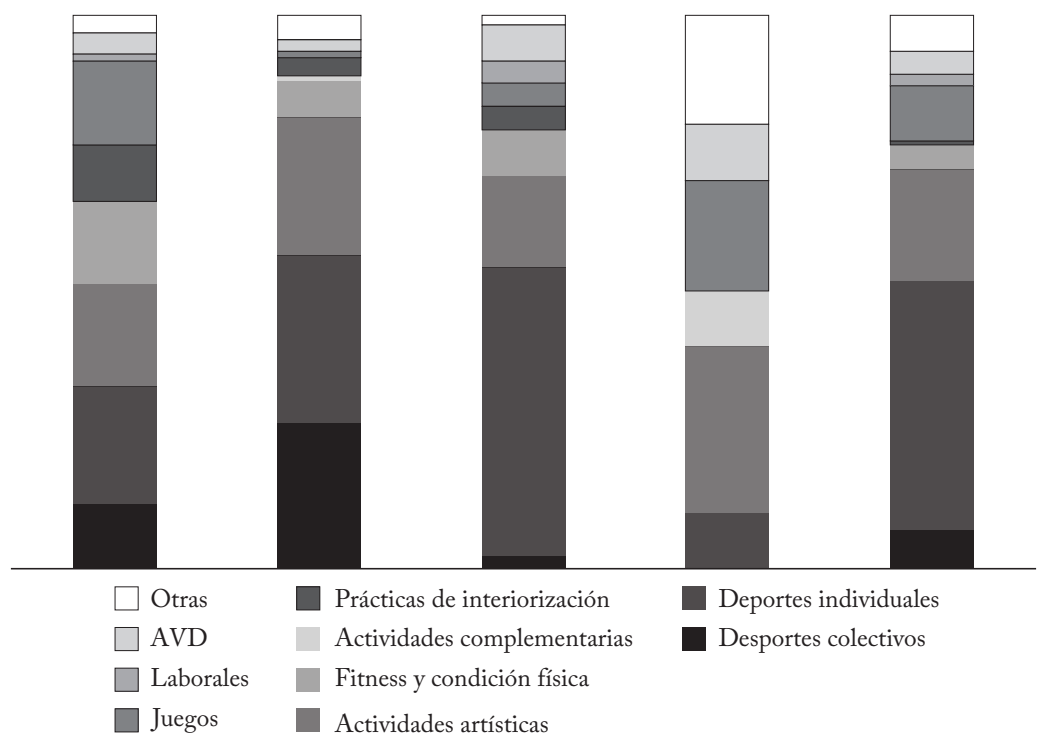

Fuente: resultados de la investigación.

Elaborado por las autoras.

Gráfico 2 - Ámbitos de práctica representados en las imágenes de los libros de texto de educación física según la edad

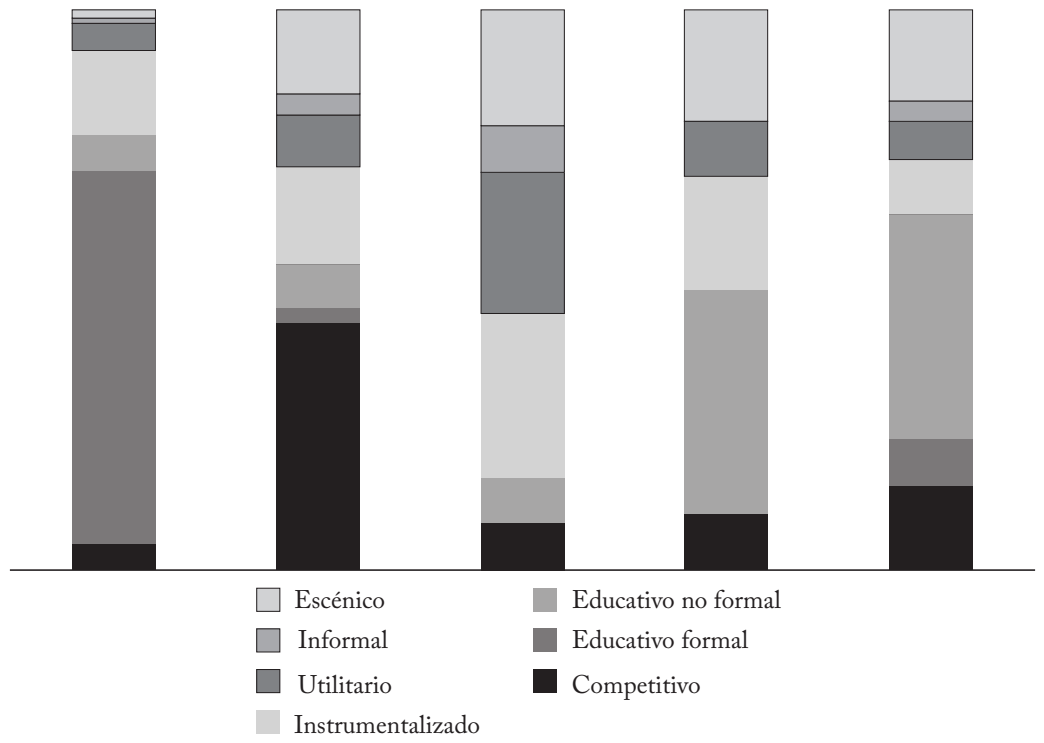

Fuente: resultados de la investigación.

Elaborado por las autoras. 
(residuo 4,7) fue significativamente mayor de lo que cabría esperar si las variables fueran independientes.

Para el cruce de variables nivel y edad el valor de $n$ fue de 682. Existieron 247 casos perdidos. De las 10 imágenes que representan personas mayores, 7 fotografías (70\%) se corresponden con actividades de no élite deportiva. Las otras 3 restantes (30\%) se ubican en la élite deportiva. El resto de franjas etarias también son fotografiadas mayoritariamente en la no élite deportiva. El cálculo de los residuos tipificados corregidos confirmó que la relación entre las variables nivel y edad es estadísticamente significativa. La probabilidad de que los personas jóvenes aparezcan realizando prácticas corporales realizadas en la élite deportiva fue significativamente mayor de lo que cabría esperar si las variables fueran independientes (residuo 10,9). Por el contrario, la probabilidad de que los niños/as-adolescentes aparezcan realizando prácticas corporales realizadas en la élite deportiva fue significativamente menor de lo que cabría esperar si las variables fueran independientes (residuo 7,8).

\section{DISCUSIÓN}

La hipótesis 1, que anticipaba que los niños y niñas, las personas adolescentes y las personas jóvenes serían las más representadas mientras que las personas adultas y las personas mayores serían las menos representadas, ha sido corroborada. Los resultados obtenidos confirmaron esta afirmación.

Los datos de la presente investigación coinciden con los aportados por Martínez (2013) y Táboas (2009) sobre los libros de texto españoles de primaria y secundaria. En estos manuales el indicador más frecuente era el de niño/as o niño-adolescente. En el caso del análisis por editoriales de los libros de texto de secundaria (Táboas, 2009) también fue más frecuente el de joven. Los libros de texto de estas editoriales - PR, SP y RS - podrían estar contribuyendo a la transmisión de los patrones hegemónicos de cultura corporal, al prevalecer los referentes icónicos asociados al modelo joven, esbelto y atlético que había sido apuntado previamente en la literatura (Táboas-Pais y Rey-Cao, 2007). Del mismo modo, los datos obtenidos

Tabla 3 - Imágenes de los diferentes grupos etarios en función del espacio

\begin{tabular}{l|c|c|c|c|c|c}
\hline \multirow{2}{*}{ Espacio } & \multicolumn{5}{c}{ EDAD } \\
\cline { 3 - 7 } \multicolumn{2}{l|}{} & $\begin{array}{c}\text { Niño/a- } \\
\text { adolescente }\end{array}$ & Joven & Adulto/a & $\begin{array}{c}\text { Persona } \\
\text { mayor }\end{array}$ & Varios \\
\hline \multirow{2}{*}{ Deportivos } & $\begin{array}{c}\text { Recuento } \\
\%\end{array}$ & 68 & 96 & 4 & 2 & 26 \\
\hline \multirow{2}{*}{ No deportivos } & $22,7 \%$ & $57,5 \%$ & $16,7 \%$ & $20 \%$ & $22,6 \%$ \\
\hline \multirow{2}{*}{ Total } & $\begin{array}{c}\text { Recuento } \\
\%\end{array}$ & 231 & 71 & 20 & 8 & 89 \\
& $\begin{array}{c}\text { Recuento } \\
\%\end{array}$ & $29,4 \%$ & $42,5 \%$ & $83,3 \%$ & $80 \%$ & $77,4 \%$ \\
\hline
\end{tabular}

Fuente: resultados de la investigación.

Elaborado por las autoras. 
corroboran que los colectivos de edad menos representados son las personas adultas (Táboas, 2009) y las personas mayores (Blanco, 2003; Botelho y Neira, 2014; Martínez,2013; Rey-Cao, Táboas-Pais y Canales-Lacruz, 2013; Torres, 2008). Debido a la función ilustrativa de la imagen puede interpretarse como lógico que los libros de texto representen en mayor medida al colectivo al que van dirigido. No obstante, dado que los libros de texto contribuyen sobremanera a construir el mundo legítimo, las editoriales y los autores/as de los libros de texto podrían cuestionarse "la representación positiva": "Una presencia intencionadamente mayor que la real para aquellos colectivos que, dañados por prejuicios, requieren de la producción de un nuevo imaginario que incremente su presencia y vinculación con acciones silenciadas hasta el momento" (Rey-Cao y González-Palomares, 2014, p. 76).

Los libros de texto de educación física centran su atención en la juventud porque este grupo de edad es el que transmite los valores centrales de la sociedad actual — vitalidad, seducción, juventud — (Le Breton, 1995). Este hecho puede provocar que el alumnado asimile estos estereotipos y acabe percibiendo a otros grupos de edades como menos capaces para participar en las mismas actividades que ellos (Robinson et al.,2007). La ausencia de representación de personas adultas, especialmente de personas mayores, puede colaborar en el refuerzo del imaginario al respecto de su incapacidad para las prácticas corporales, y a su exclusión del campo de las prácticas físico-deportivas (Rey-Cao, Táboas-Pais y Canales-Lacruz, 2013).

Los manuales analizados no satisfacen las recomendaciones al respecto de la representación de la edad (Rey-Cao y González-Palomares, 2014) porque deberían evitar la invisibilización y estereotipación de las personas mayores. Además, la escasez de imágenes intergeneracionales tampoco favorece la transmisión de modelos de vivencia corporal inclusiva.

La hipótesis 2, que anticipaba que la representación de las mujeres mayores sería muy inferior a la de los hombres mayores, no ha sido corroborada. Los datos encontrados en los libros de texto de educación física de Brasil no coinciden con estudios precedentes que pusieron de manifiesto la invisibilidad de las mujeres mayores en los materiales curriculares españoles (Rey-Cao, Táboas-Pais y Canales-Lacruz, 2013).

No obstante, los resultados para el cruce de variables entre sexo y edad ha sido significativo en algunas franjas etarias. Los datos han revelado una asociación entre la representación de niñas, mujeres adolescentes y grupos mixtos en la infancia, y la de hombres en la juventud y la edad adulta. Este hecho es acorde a la literatura que manifiesta que los libros de texto reducen la complejidad propia de la realidad social (Gallardo, 2001; Jorquera, 2010) y establecen un micromundo sesgado que reproduce en muchas ocasiones legitimaciones del orden social establecido (Bernete, 1994) y desigualdades vigentes (Atienza, 2007; Moeglin,2005). La reproducción de esta desigual presencia de hombres y mujeres en diferentes franjas de edad podría deberse a que la educación física es obligatoria para ambos sexos durante la edad escolar. Sin embargo en la juventud y la edad adulta se representan más hombres realizando prácticas corporales en consonancia a los bajos porcentajes de participación de las mujeres en estas edades (Azevedo, Araújo y Pereira Junior, 2006). Esta situación debería evitarse para no legitimar a través de los libros de texto la 
menor participación en la cultura corporal hegemónica de las mujeres. Al mismo tiempo la inclusión de imágenes de mujeres jóvenes, adultas y mayores vinculadas a prácticas corporales no hegemónicas favorecería el empoderamiento de otras corporeidades femeninas: prácticas corporales vinculadas al cuidado y relación filial, técnicas corporales de subjetivización o "de uso de sî" con una pedagogía emancipadora (Gómez, 2008), prácticas de juego simbólico y de trabajo manual y artesano.

La hipótesis 3, que anticipaba que la mayoría de las personas mayores se representarían con un enfoque medio, practicando deportes individuales y juegos tradicionales en ámbitos de carácter recreativo, espacios no deportivos y en niveles de práctica no vinculados a la élite, ha sido corroborada parcialmente.

El análisis semiótico de las imágenes de los libros de texto de educación física evidenció que las personas mayores fueron enfocadas mayoritariamente de forma neutra, con un enfoque medio. Estos datos coinciden con los datos aportados en investigaciones similares con libros de texto de España (Rey-Cao, Táboas-Pais y Canales-Lacruz, 2013). No obstante el estudio de los materiales curriculares españoles evidenció mayor número de imágenes de personas mayores con enfoques picados que otorgan al personaje un aire de debilidad y menor importancia (Alonso y Matilla, 1990), mientras que en los libros analizados en este trabajo sucede lo contrario. El número de imágenes de personas mayores con enfoques contrapicados es el más abundante, caracterizándolas como poderosas e importantes (Alonso y Matilla, 1990). Este dato parece desvelar que la cultura al respecto de las personas mayores que transmiten los libros de texto de Brasil privilegia su consideración social, aspecto que no sucedió en el caso de los libros de texto españoles.

Aunque en el resto de franjas etarias también ha predominado el enfoque medio, los datos revelaron una asociación significativa entre los jóvenes y los enfoques contrapicados. Las personas jóvenes son enfocadas desde abajo transmitiendo importancia y superioridad. Este hecho, sumado a su mayor presencia en los manuales analizados, refuerza la idea de la prevalencia de referentes icónicos asociados al modelo joven, esbelto y atlético (Táboas-Pais y Rey-Cao, 2007). Con los niños/ as-adolescentes sucede lo contrario, presentan muy pocas probabilidades de ser enfocados con este tipo de ángulo, lo que sugiere que esta franja de edad es vista como poco importante y débil.

El análisis efectuado sobre el tipo de prácticas corporales en las que aparecen representadas las personas mayores coincide parcialmente con los datos aportados por Rey-Cao, Táboas-Pais y Canales Lacruz (2013). Estas autoras evidenciaron que los juegos, los deportes individuales y las actividades de la vida diaria eran las prácticas corporales más practicadas por este colectivo en los libros de texto de educación física españoles. Sin embargo, los resultados de este estudio han demostrado que las personas mayores son más representadas realizando actividades artísticas, juegos y otros tipos de actividades. Estos datos están más en consonancia con el estudio de Becerril (2011) que encontró que las actividades representadas en las portadas de la revista "60 y más" eran los juegos de pelota, los paseos y el baile. En el caso del presente estudio las personas mayores no están vinculadas a las prácticas deportivas modernas y realizan prácticas corporales propias de una cultura corporal no sometida a la homogeneización cultural que conlleva el proceso deportivizador (Lagardera, 
1992). Las personas mayores se constituyen como un colectivo legitimado para incorporar capitales corporales ajenos al modelo hegemónico - fuerte, vigoroso, rápido, competitivo, vertiginoso - Estos capitales marginales que desvelan las expresiones motrices que practican las personas mayores se asociarían a la contemplación, la expresión emocional, el ensimismamiento y la calma. Esta vinculación es acorde al tiempo de júbilo, de ocio que le otorga la sociedad a las personas de edad.

Con respecto al resto de franjas etarias, aunque el resultado del cruce con la variable tipo de práctica no fue significativo, el análisis de los porcentajes reveló que hay prácticas corporales que predominan sobre otras. En general, la práctica corporal más representada en la infancia, la juventud, la edad adulta y los grupos intergeneracionales, son los deportes individuales. Otra de las prácticas corporales que realizan todas las franjas etarias son las actividades artísticas. Este dato no coincide con los aportados por Táboas-Pais y Rey-Cao (2012) en el estudio de los contenidos presentes en las imágenes de los libros de texto de educación física de secundaria en España. Estas autoras encontraron que el bloque de contenidos más representado era el de "Juegos y Deportes" y el que menos se representaba era el de "Artísticas y Expresión Corporal". En el presente estudio los juegos son mayoritariamente practicados por la infancia y por los grupos intergeneracionales y los deportes -tanto individuales como colectivos- por las personas jóvenes. Esta última atribución es coincidente con el análisis descriptivo realizado en los libros de texto españoles (Táboas-Pais y Rey-Cao, 2007) que reveló que las personas jóvenes siguen apareciendo como las destinatarias del deporte. El bloque de "Condición física y fitness" en este estudio se relaciona con las personas adultas. Esta asignación de tipo de prácticas puede ser un reflejo del cosmos social que reproducen los libros de texto, que representan lo real a partir del imaginario social dominante: los niños y las niñas juegan, las personas jóvenes practican deportes, las personas adultas se ponen en forma en su tiempo de ocio y las personas mayores bailan y juegan.

Con respecto al ámbito de práctica, los datos obtenidos en el análisis de las imágenes de los libros de texto de educación física coinciden con los obtenidos por Becerril (2011) y Rey-Cao, Táboas-Pais y Canales-Lacruz (2013). La mayoría de las personas mayores realizan prácticas en ámbitos de carácter recreativo, principalmente en ámbitos educativos formales, informales y escénicos. Con respecto al resto de franjas etarias, aunque los resultados de estos cruces de variables no han sido significativos, en el análisis de los porcentajes se encontró que cada grupo de edad está asociado a un ámbito determinado. En el caso de los niños/as-adolescentes el ámbito en el que están representados es el educativo formal. Esto es lógico ya que en esa franja etaria pasan la mayor parte del tiempo en las aulas. Las personas jóvenes se ubican en el ámbito competitivo. Esto puede ser debido a que es en este tramo de edad cuando más tiempo se dedica al deporte y a la competición. De nuevo los contenidos visuales afianzan el modelo icónico del joven atlético. Por último, las personas adultas se ubican con los ámbitos informales y utilitarios. Esto nos hace ver que la edad adulta se relaciona en el imaginario que transmiten los libros de texto con las prácticas corporales en tiempos de ocio o con la realización de las tareas relacionadas con el hogar. 
Con respecto al espacio de práctica, los resultados obtenidos coinciden con la literatura previa al encontrar que las personas mayores se representan mayoritariamente realizando prácticas corporales en espacios no deportivos (Becerril, 2011; Rey-Cao, Táboas-Pais y Canales-Lacruz, 2013). Este dato refuerza la idea de que el imaginario sobre la cultura corporal de las personas mayores no está vinculado a la deportivización. Para el resto de franjas etarias, los resultados de su asociación con determinados espacios de práctica han sido significativos. Las imágenes de los libros de texto de educación física asocian a la juventud con los espacios deportivos. Esto es evidente ya que las prácticas corporales más representadas para este colectivo de edad son los deportes. Por el contrario, los niños/as-adolescentes se asocian de forma significativa con los espacios no deportivos. Este dato puede deberse a que, aunque este grupo de edad se ubica principalmente en el ámbito educativo formal, no todos los colegios disponen de espacios deportivos propiamente dichos.

Con relación al nivel de práctica, los resultados corroboran los datos aportados por Rey-Cao, Táboas-Pais y Canales-Lacruz (2013). Estas autoras habían evidenciado que las personas mayores aparecían representadas en los libros de texto realizando prácticas alejadas del alto rendimiento. Los resultados del Ji-Cuadrado para este cruce de variables indican que las imágenes de los libros de texto de educación física asocian la juventud con prácticas relacionadas con el alto rendimiento mientras que la infancia y adolescencia están asociadas a prácticas no relacionadas con la élite.

Los resultados manifiestan que los libros de texto analizados no atienden a las recomendaciones encontradas en la literatura (Rey-Cao y González-Palomares, 2014) al respecto de evitar la representación excesiva de una franja etaria asociada a una determinada actividad físico-deportiva, ámbito o espacio y de incorporar imágenes de personas adultas y personas mayores de ambos géneros participando en una amplia variedad de actividades físico-deportivas, evitando limitar su representación asociada a la práctica de actividades de la vida diaria o a juegos tradicionales.

\section{CONCLUSIONES}

Los libros de texto de educación física transmiten una cultura corporal sesgada por la edad. Los grupos de edad fragilizados en su participación social las personas mayores - tienen una limitada representación que contribuye a su invisibilización y a la construcción de un imaginario que las excluye de una experiencia corporal diversificada. Si bien los libros de texto de educación física presentan en sus imágenes a las personas mayores con un enfoque que privilegia su consideración como personas importantes y poderosas, reproducen una cultura corporal más vinculada a la niñez, la adolescencia y la juventud. Esta construcción puede comprometer, no solo el juicio social al respecto de las prácticas corporales que realizan las personas mayores, sino la elección del alumnado de prácticas corporales futuras. La experiencia corporal que se legitima en los libros de texto se corresponde con un imaginario que sesga por:

Género y edad. Las niñas, mujeres adolescentes y grupos mixtos son visibles en la infancia; pero en la juventud y edad adulta prevalecen los hombres. 
Edad y tipo de práctica corporal. Niños y niñas juegan, personas jóvenes practican deportes, personas adultas se ponen en forma en su tiempo de ocio y personas mayores bailan y juegan. El proceso deportivizador al que ha sido sometido la cultura corporal es más presente en el colectivo de la juventud. Los libros de texto representan en sus imágenes el ideal de la juventud asociada a la práctica deportiva competitiva y relacionada con la élite. El resto de franjas etarias se representan en otros tipos de práctica corporales, con un predominio generalizado de los deportes individuales y las actividades artísticas, ubicados en ámbitos no competitivos, en espacios no deportivos y en actividades alejadas de la élite deportiva.

Es importante que tanto el profesorado como las editoriales que publican libros de texto analicen los materiales antes de ser presentados al alumnado y eviten que los estereotipos presentes en las imágenes se continúen perpetuando en sociedades futuras. Las imágenes de los libros de texto deben seleccionarse atendiendo a su coherencia con los objetivos y finalidades del sistema educativo. En la actualidad las imágenes obedecen más a una función representativa, pero no prospectiva. Es decir, las imágenes reproducen los estereotipos e imaginario vigente, en lugar de obedecer a su funcionalidad: Construir el modelo social que determinan los objetivos educativos.

\section{REFERENCIAS}

Alonso, M.; Matilla, L. Imágenes en acción: análisis y práctica de la expresión audiovisual en la escuela activa. Madrid: Akal, 1990.

Atienza, E. Discurso e ideología en los libros de texto de ciencias sociales. Discurso E Sociedad, [S.1.: s.n], v. 1, n. 4, p. 543-574, 2007.

Azevedo Junior, Mario R. D.; Araújo, C. L. P.; Pereira, F. M. Atividades físicas e esportivas na adolescência: mudanças de preferências ao longo das últimas décadas. Revista Brasileira de Educação Física e Esporte, São Paulo: USP, v. 20, n. 1, p. 51-58, 2006. BARbero, J. I. Cultura corporal: ¿tenemos algo que decir desde la educación física? Ágora para la Educación Física y el Deporte, Valladolid: Universidad de Valladolid, n. 1, p. 18-36, sept. 2001.

. Deporte y cultura: de la modernidad a los discursos posmodernos del cuerpo. Educación Física y Deporte, Antioquia: Universidad de Antioquia, v. 25, n. 1, p. 69-93, 2006.

. La escolarización del cuerpo: reflexiones en torno a la levedad de los valores del capital "cuerpo" en educación física. Revista Iberoamericana de Educación, [S.1.]: OEI, n. 39, p. 25-51, 2005.

Bauman, Z. Modernidad líquida. Buenos Aires: Fondo de Cultura Económica de Argentina, 2000.

Becerril, R. Cuerpo, cultura y envejecimiento. Análisis de la imagen corporal en la publicación "60 y más" (IMSERSO). Ágora para la Educación Física y el Deporte, Valladolid: Universidad de Valladolid, v. 13, n. 2, p. 139-164, mayo/agosto 2011. 
Bernete, F. Cómo analizar las representaciones sociales contenidas en los libros de texto de Historia. CL E E: Comunicación, Lenguaje y Educación, [S.1.]: Fundación Infancia y Aprendizaje, n. 22, p. 59-74, 1994.

Blanco, N. La imagen del mundo: la representación de mujeres y varones en textos de educación secundaria obligatoria. In: Villuendas, M. D.; Gordo, Á. J. (Orgs.). Relaciones de género en psicología y educación. Madrid: Consejería de Educación, 2003.

Botelho, R.; Neira, M. Análisis de libros de texto en Brasil y en España: Una introducción al tema en el área de educación física. Movimento, Porto Alegre: UFRGS, v. 20, n. 2, p. 659-685, abr./jun. 2014.

Bourdieu, P. El sentido práctico. Madrid: Siglo XXI, 2008.

Brasil. Secretaria de Educação Fundamental. Parâmetros Curriculares Nacionais: Educação Física. Brasília, DF: 1998. Disponible en: <http://portal.mec.gov.br/seb/ arquivos/pdf/fisica.pdf>. Acceso en: 11 enero 2015.

. Lei Federal n. 10.741, de 1 de outubro de 2003. Dispõe sobre o Estatuto do Idoso e dá outras providências. Diário Oficial da União, Brasília, DF, Secretaria Especial dos Direitos Humanos, 3 out. 2003. Disponible en: <http://www.planalto.gov.br/ ccivil_03/leis/2003/110.741.htm>. Acceso en: 11 enero 2015.

Cachioni, M.; Aguilar, L. E. Crenças em relação à velhice entre alunos da graduação, funcionários e coordenadores professores envolvidos com as demandas da velhice em universidades brasileiras. Kairós, São Paulo: PUC, v. 11, n. 2, p. 95-119, dez. 2008.

Carbajo, M. C. Mitos y estereotipos sobre la vejez. Propuesta de una concepción realista y tolerante. Ensayos, Albacete: Facultad de Educación de Albacete, n. 24, p. 87-96, 2009.

Caspistegui, F. Deporte e identidad, o sobre cómo definirnos. Historia y Comunicación Social, Madrid: Universidad Complutense de Madrid, v. 17, p. 19-39, 2012.

DAolio, J. Os significados do corpo na cultura e as implicações para a educação física. Movimento, Porto Alegre: UFRGS, v. 2, n. 2, p. 24-28, 1995.

De La Orden, A. Evaluación y calidad: análisis de un modelo. Estudios sobre Educación, Navarra: Universidad de Navarra, n. 16, p. 17-36, jun. 2009.

Elias, N.; Dunning, E. Deporte y ocio en el proceso de la civilización. México: Fondo de Cultura Económica, 1992.

Fernández, C. Estereotipos sobre la vejez y niveles de independencia. Geriátrika, Madrid: Alpe Editores, v. 19, n. 9-10, p. 310-316, 2003.

Fleuri, R. M. Intercultura e educação. Revista Brasileira de Educação, Rio de Janeiro: ANPEd; Campinas: Autores Associados, n. 23, p. 16-35, maio/ago. 2003.

Gallardo, I. Una aventura educativa: el uso del libro de texto hacia el siglo XXI. Educación, Costa Rica: Universidad de Costa Rica, v. 25, n. 1, p. 81-93, 2001.

Gazquez,J.J.; Pérez-Fuentes, M. C.; Fernández, M.; González,L.; Ruiz, I.; Díaz, A. Old-age stereotypes related to the gerontology education: an intergenerational study. European Journal of Education and Psychology, Almería: Elservier, v. 2, n. 3, p. 263-273, nov. 2009. 
Goldstein, S. B.; Siegel, D.; Seaman, J. Limited access: the status of disability in introductory psychology textbooks. Teaching of Psychology, United States: Sage Publications, v. 37, n. 1, p. 21-27, jan. 2010.

Gomes da Silva, F.A.; Silva, L.A.; LüDorf, S.M. A educação física no ensino médio: um olhar sobre o corpo. Movimento, Porto Alegre: UFRGS, v. 21, n. 3, p. 673-685, jun. 2015. Gómez,Z. De la educación física y el uso de sí: ejercicios estético-políticos de la cultura somática moderna. Movimento, Porto Alegre: UFRGS, v. 14, n. 2, p. 13-37, set. 2008.

Gubern, R. Patologias de la imagen. Barcelona: Anagrama, 2005.

Heinemann, K. Introducción a la metodología de la investigación empirica en las ciencias del deporte. Barcelona: Paidotribo, 2003.

Ivic, S. O direito dos idosos na União Europeia. Dados, Rio de Janeiro: UERJ, n. 56, n. 1, p. 185-205, 2013.

Joly, M. La interpretación de la imagen: entre memoria, estereotipo y seducción. Barcelona: Paidós, 2003.

Jorquera, P. Vejez y envejecimiento: imaginarios sociales presentes en los textos escolares oficiales del Ministerio de Educación chileno. Revista MAD, Santiago de Chile: Universidad de Chile, n. 22, p. 132-165, 2010.

Knudsen, S. V. Intersectionality. A theoretical inspiration in the analysis of minority cultures and identities in textbooks. In: Bruillard, É.; Aamotsbakken, B.; KNudsen, S. V.; Horsley, M. (Orgs.). Caught in the web or lost in the textbook? Eighth International Conference on Learning and Educational Media. Francia: Iartem, 2005. p. 61-76.

Lagardera, F. Introducción de la gimnástica en el Sistema Educativo Español (De práctica aristocrática a su transformación en praxis deportiva en el marco de una sociedad decimonónica en busca de la modernidad). In: International Standing Conference for the History of Education, 1992, Barcelona. Education, physical activities and sport in a historical perspective. Anales... Barcelona, España, 1992.

Lazzarotti Filho, A.; Silva, A. M.; Antunes, P. C.; Silva, A. P. S.; Leite, J. O. O termo práticas corporais na literatura científica brasileira e sua repercussão no campo da educação física. Movimento, Porto Alegre: UFRGS, v. 16, n. 1, p. 11-29, 2010.

Le Breton, D. Antropología del cuerpo y modernidad. Buenos Aires: Nueva Visión, 1995. Magaly, R. La vejez en tiempos de modernidad líquida: incertidumbres y el temor al envejecimiento. Florionápolis: AGBook, 2011.

Martínez, V.Cuerpos silenciados y educación inclusiva: análisis de las imágenes de libros de textos españoles de educación primaria. Revista Latinoamericana de Educación Inclusiva, Santiago de Chile: Universidad Central de Chile; RINACE, v. 7, n. 2, p. 213-229, 2013. Moeglin, P.The textbook and after... In: Bruillard, É.; Aamotsbakken, B.; Knudsen, S. V.; Horsley, M. (Orgs.). Caught in the web or lost in the textbook? Eighth International Conference on Learning and Educational Media. Francia: Iartem, 2005. p. 15-33.

Moreno, H. La invención del cuerpo atlético. AIBR, Madrid, Antropólogos Iberoamericanos en Red, v. 8, n. 1, p. 49-81, 2013. 
Moscoso, D.; Martín, M. Deporte y ejercicio físico en la configuración de los estilos de vida. In: Moscoso, D.; Moyano, E. (Orgs.). Deporte, salud y calidad de vida. Barcelona: Fundación "la Caixa", 2009. (Colección Estudios Sociales, v. 26). p. 19-57.

Moscoso, D.; Moyano, E. Conclusiones. In: . (Orgs.). Deporte, salud y calidad de vida. Barcelona: Fundación "la Caixa", 2009. (Colección Estudios Sociales, v. 26). p. 198-213.

Mosquera, M. J.; Puig, N. Género y edad en el deporte. In: García, M.; Otero, F. L. (Orgs.). Sociología del deporte. Madrid: Alianza Editorial, 2002. p. 99-132.

Muñoz, B. Conocimiento experto, consumo y cuerpo: relaciones "en" y "para" la hipermodernidad. Ágora para la Educación Física y el Deporte, Valladolid: Universidad de Valladolid, n. 4-5, p. 7-19, 2007.

Olivera, A.; Olivera, J. Propuesta de una clasificación taxonómica de las actividades físicas de aventura en la naturaleza. Marco conceptual y análisis de los criterios elegidos. Apunts Educación Física y Deportes, Barcelona: INEFC, n. 41, p. 108-123, 1995.

Oliveira, S. Texto visual, estereótipos de gênero e o livro didático de língua estrangeira. Trabalhos em Linguistica Aplicada, Campinas: UNICAMP, v. 47, n. 1, p. 91-117, jan./ jun. 2008.

Revuelta, J. Pedagogía de la imagen: lectura crítica de publicidad televisiva. Comunicar, Huelva: Grupo Comunicar Ediciones, v. 31, n. 16, p. 613-621, oct. 2008.

Rey-Cao, A.; González-Palomares, A. Criterios de evaluación para la selección de imágenes libres de estereotipos en los libros de texto. Enseñanza E Teaching, Salamanca: Universidad de Salamanca, v. 32, n. 2, p. 73-96, 2014.

Rey-Cao, A.; Táboas-Pais, M. I.; Canales-Lacruz, I. La representación de las personas mayores en los libros de texto. Revista de Educación, Madrid: Ministerio de Educación, Cultura y Deporte, n. 362, p. 129-153, 2013.

Robinson, T.; Callister, M.; Magoffin, D.; Moore, J. The portrayal of older characters in Disney animated films. Journal of Aging Studies, Missouri: University of Massachusetts at Amherst, v. 21, n. 3, p. 203-213, ago. 2007.

Rodrigues, H. A.; Darido, S. C. O livro didático na educação física escolar: a visão dos professores. Motriz, São Paulo: UNESP, v. 17, n. 1, p. 48-62, jan./mar. 2011.

Scortegagna, P. A.; Oliveira, R. C. Idoso: um novo ator social. In: Seminário de Pesquisa em Educação da Regiño Sul, 9., 2012, Caxias do Sul. Anais... Caxias do Sul, 29-1, jul./ago. 2012. p. 1-17.

Sсотт, J. W. Gender: a useful category of historical analysis. The American Historical Review, Washington: American Historical Association, v. 91, n. 5, p. 1.053-1.075, 1986. Silva, A.; LüDorg, S. M. A.; Silva, F. A. G.; PAlma, A. A visão de corpo na perspectiva de graduandos em educação física: fragmentada ou integrada? Movimento, Porto Alegre: UFRGS, v. 15, n. 3, p. 109-126, jul./set. 2009.

Sleeter, C. E.; Grant, C. A. Race, class, gender and disability in current textbooks. In: Provenzo, E. F.; Bello, M.; Shaver, A. N. (Orgs.). The textbook as discourse: sociocultural dimensions of American schoolbooks. New York: Routledge, 2011. p. 183-215. 
ТÁводs, M. I. Análisis de los estereotipos corporales y de los modelos de actividad física representados en las imágenes de los libros de texto de Educación Física. 2009. 525 p. Tesis (Doctorado en Didácticas Especiales, Educación Física y Deportiva) - Universidade de Vigo, Pontevedra, 2009.

TÁboas-PAis, M. I.; Rey-CaO, A. Los contenidos de la educación física en secundaria: un análisis de las actividades físicas que se enseñan desde las imágenes de los libros de texto. Apunts. Educación Física y Deportes, Barcelona: INEFC, n. 107, p. 45-53, enero/ marzo 2012.

Táboas-Pais, M. I.; Rey-CaO, A. El cuerpo en las imágenes de los libros de texto de educación física: análisis de dos editoriales. Kronos, Madrid: Universidad Europea de Madrid, v. 6, n. 11, p. 10-15, enero/jun. 2007.

TAffarel, C. N. Desporto educacional: realidade e possibilidades das políticas governamentais e das práticas pedagógicas nas escolas públicas. Movimento, Porto Alegre: URGS, v. 6, n. 13, p. 15-35, 2000.

Torres, J. Diversidad cultural y contenidos escolares. Revista de Educación, Madrid: Ministerio de Educación, Cultura y Deporte, n. 345, p. 83-110, enero/abr. 2008.

VÁzQUEz, B. Los valores corporales y la educación física: hacia una reconceptualización de la educación física. Ágora para la Educación Física y el Deporte, Valladolid: Universidad de Valladolid, n. 1, p. 7-17, sept. 2001.

Vicente, M. De la diversidad del concepto de deporte y su naturaleza. La sospechosa (in)definición del concepto. Kinesis: Ciencias del Deporte, Educación Física y Recreación, Armenia, Colombia: Editorial Kinesis, n. 37, p. 5-18, 2003.

\section{SOBRE LAS AUTORAS}

Alba González Palomares es doctora en investigaciones en didácticas especiales y educación física y deportiva por la Universidad de Vigo (España). Profesora de la Universidad Pontificia de Salamanca (España).

E-mail: agonzalezpa@upsa.es

Ana Isabel Rey-Cao es doctora en educación física por la Universidad de Coruña (España). Profesora de la Universidade de Vigo (España).

E-mail: anacao@uvigo.es

Recebido em 25 de março de 2015 Aprovado em 16 de fevereiro de 2016 